University of Nebraska - Lincoln

DigitalCommons@University of Nebraska - Lincoln

Faculty Papers and Publications in Animal

Science

Animal Science Department

March 1999

\title{
Genotypic Expression at Different Ages: II. Wool Traits of Sheep
}

H. Okut

University of Nebraska-Lincoln

C. M. Bromley

University of Nebraska-Lincoln

L. Dale Van Vleck

University of Nebraska-Lincoln, dvan-vleck1@unl.edu

G. D. Snowder

USDA-ARS, U.S. Sheep Experiment Station, Dubois, ID

Follow this and additional works at: https://digitalcommons.unl.edu/animalscifacpub

Part of the Animal Sciences Commons

Okut, H.; Bromley, C. M.; Van Vleck, L. Dale; and Snowder, G. D., "Genotypic Expression at Different Ages: II. Wool Traits of Sheep" (1999). Faculty Papers and Publications in Animal Science. 281.

https://digitalcommons.unl.edu/animalscifacpub/281

This Article is brought to you for free and open access by the Animal Science Department at DigitalCommons@University of Nebraska - Lincoln. It has been accepted for inclusion in Faculty Papers and Publications in Animal Science by an authorized administrator of DigitalCommons@University of Nebraska - Lincoln. 


\title{
Genotypic Expression at Different Ages: II. Wool Traits of Sheep ${ }^{1}$
}

\author{
H. Okut*,2, C. M. Bromley*, L. D. Van Vleckt,3, and G. D. Snowder‡ \\ *Department of Animal Science, University of Nebraska, Lincoln 68583; †ARS, USDA, \\ Roman L. Hruska U.S. Meat Animal Research Center, Lincoln 68583; and ¥ARS, \\ USDA, U.S. Sheep Experiment Station, Dubois, ID 83423
}

\begin{abstract}
Genetic parameters for wool traits for Columbia, Polypay, Rambouillet, and Targhee breeds of sheep were estimated with single- and multipletrait analyses using REML with animal models. Traits considered were fleece grade, fleece weight, and staple length. Total number of observations ranged from 11,673 to 34,746 for fleece grade and fleece weight and from 3,500 to 11,641 for staple length for the four breeds. For single-trait analyses, data were divided by age of ewe: young ages (age of $1 \mathrm{yr}$ ), middle ages (ages of 2 and $3 \mathrm{yr}$ ), and older ages (age greater than $3 \mathrm{yr}$ ). Heritability estimates averaged over breeds for fleece grade decreased from .42 at a young age to .37 for older ages. For fleece weight, heritability estimates averaged .52, .57, and .55 within the successively older groups. Heritability estimates for staple length averaged .54 for young and middle age classes. Few older ewes had staple length measurements. After single-trait analyses, new data sets were created for
\end{abstract}

three-trait analyses with traits defined by three age classes when animals were measured. Heritability estimates with three-trait analyses, except for a few cases, were somewhat greater than those from singletrait analyses. For fleece grade, the genetic correlations averaged over breeds were .72 for young with middle, .42 for young with older, and .86 for middle with older age classes. For fleece weight, the average genetic correlations were .81, .83, and .98. For staple length, the average genetic correlation for young with middle age classes was .82. Estimates of genetic correlations across ages varied considerably among breeds. The average estimates of correlations suggest that fleece grade may need to be defined by age, especially for the Columbia and Rambouillet breeds. For fleece weight and staple length, however, the average correlations suggest no need to define those traits by age.

Key Words: Breeds, Genetics, Genotypes

(o1999 American Society of Animal Science. All rights reserved.

J. Anim. Sci. 1999. 77:2366-2371

\section{Introduction}

Several studies have been conducted (I man et al., 1992; Saboulard, 1995; Notter and Hough, 1997; van Zyl, 1998) to estimate genetic correlations among wool traits. Fogarty (1995) has provided a summary of such studies. Recently, studies of genetic correlations across ages for Merino wool traits (Atkins and Mortimer, 1987; Coelli et al., 1998; Atkins, 1990) have suggested the importance of considering age-specific

\footnotetext{
${ }^{1}$ Published as paper no. 12368, J ournal Ser., Nebraska Agric. Res. Div., Univ. of Nebraska, Lincoln 68583-0908. Partial support of the senior author by NATO Science Fellowship Programmed by the Scientific and Technical Research Council (TUBITAK) of Turkey.

${ }^{2}$ Current address: Faculty of Agriculture, Yuzuncu Yil Universitesi Ziraat Fakultesi, 65080 Van, Turkey.

${ }^{3}$ To whom correspondence should be addressed: A218 Animal Sciences, Univ. of Nebraska, Lincoln 68583-0908 (phone: 402/ 472-6010; fax: 402/472-6362).

Received October 26, 1998.

Accepted March 31, 1999.
}

traits for improving selection response. Analyzing data for each age at measurement separately may provide additional information for making selection decisions. The objective of this study was to estimate parameters necessary to determine whether in a selection program more progress can be made by considering the age of the animal as a part of the trait (Falconer, 1952), rather than by simply adjusting for the age of the animal.

\section{Materials and Methods}

\section{Data and Traits}

Data for this study were collected at the United States Sheep Experiment Station, Dubois, ID, during the period 1974 to 1996 for Columbia, Polypay, Rambouillet, and Targhee sheep. Shearing was conducted in late May at the headquarters facility. All sheep over $8 \mathrm{mo}$ of age were shorn. Fleeces were weighed. Staple length was measured prior to shear- 
ing at midside without stretching the fiber. Before 1990, three measures were taken at midside by different individuals and averaged. Since 1990, measurement was based on a single measure. After shearing, fleeces were skirted and graded. Fleece grade was assigned by a subjective, visual appraisal of fiber diameter based on the English Worsted Yarn Count System and, therefore, converted to spinning count. Day of year shorn was recorded as well as sex of animal and year shorn. Basic statistics of the data are shown in Table 1. Fleece weight, fleece grade, and staple length were the traits analyzed in this study. A more detailed description of management can be found in Ercanbrack and Knight (1998). The data were analyzed previously by van Zyl (1998) to estimate correlations among and between prolificacy, weight, and wool traits.

For this study of genotype $\times$ age interaction, the data for each wool trait within each of the four breeds initially were divided into 10 data subsets by age of animal in years at measurement such that 120 singletrait analyses ( 4 breeds $\times 10$ age classes $\times 3$ traits) were performed. For all breeds, estimates of parameters were not reasonable for some age classes, in particular for age 5 and older classes, because of small numbers of measurements for those ages. Therefore, the data were divided into subsets by three ages of animals: young age (age $1 \mathrm{yr}$ ), middle ages (ages 2 and $3 \mathrm{yr}$ ), and older ages (age greater than 3 $\mathrm{yr}$ ). Then, a total of 36 single-trait analyses (4 breeds $\times 3$ age classes $\times 3$ traits) were performed to obtain starting values for estimates of (co)variances for three-trait analyses.

After the single-trait analyses, new data sets were created for three-trait analyses with same-named traits defined by age class of the ewe when the trait was measured. All pedigree information from 1974 to 1996 was used. Levels of random and fixed effects that should be included in the linear mixed model for each trait and age group were included for the newly created data set. This pattern allowed use of all relationships including animals in all subsets of samenamed traits in three-trait analyses. A ewe could be measured at most once at the young age and twice in the middle age group but more often in the older age group. Outliers were discarded from data sets to reduce possible influence on estimates of variance. If the absolute value of a measurement minus the unadjusted mean divided by the unadjusted phenotypic standard deviation was greater than 4.5 the observation was not used in the analysis.

\section{Statistical Analysis}

Analysis procedures were similar to those described in the preceding article (Okut et al., 1999), except that mating sire effects were not included in the model.

The linear animal model used to estimate variance components for the single-trait analyses was as follows:

$$
\mathbf{y}=\mathbf{X} \boldsymbol{\beta}+\mathbf{Z} \mathbf{u}_{\mathrm{a}}+\mathbf{P} \mathbf{u}_{\mathrm{pe}}+\mathbf{e}
$$

where $\mathbf{y}$ is a vector of observations, $\beta$ is the vector of unknown fixed effects, $\mathbf{u}_{a}$ is the vector of unknown direct additive genetic effects of the animals, and $\mathbf{u}_{\mathrm{pe}}$ is the vector of unknown uncorrelated permanent environmental effects of the animals, with association matrices $\mathbf{X}, \mathbf{Z}$, and $\mathbf{P}$; e is a vector of random residual

Table 1. Summary by breed and age of ewe class of number of measurements (n), sires (s), and ewes (a) with records with unadjusted means and standard deviations (SD) for fleece weight and fleece grade and for staple length

\begin{tabular}{|c|c|c|c|c|c|c|c|c|c|c|c|c|c|c|c|}
\hline \multirow[b]{2}{*}{ Breed and age group } & \multicolumn{5}{|c|}{ Fleece grade, spinning count } & \multicolumn{5}{|c|}{ Fleece weight, $\mathrm{kg}$} & \multicolumn{5}{|c|}{ Staple length, $\mathrm{cm}$} \\
\hline & $\mathrm{n}$ & s & a & Mean & SD & $\mathrm{n}$ & $\mathrm{s}$ & a & Mean & $\mathrm{SD}$ & $\mathrm{n}$ & $\mathrm{s}$ & a & Mean & SD \\
\hline \multicolumn{16}{|l|}{ Columbia } \\
\hline Young & 4,236 & 286 & 4,236 & 57.54 & 2.67 & 4,236 & 286 & 4,236 & 5.14 & 1.24 & 3,271 & 276 & 3,271 & 9.36 & 1.89 \\
\hline Middle & 4,326 & 267 & 2,608 & 57.55 & 2.62 & 4,362 & 267 & 2,608 & 5.07 & 1.06 & 319 & 156 & 308 & 9.65 & 1.70 \\
\hline Older & 3,075 & 206 & 1,284 & 57.05 & 2.41 & 3,075 & 206 & 1,284 & 5.15 & .93 & - & - & - & - & - \\
\hline \multicolumn{16}{|l|}{ Polypay } \\
\hline Young & 13,432 & 862 & 13,432 & 57.94 & 3.14 & 13,432 & 862 & 13,432 & 3.74 & 1.13 & 10,663 & 761 & 10,663 & 8.67 & 1.89 \\
\hline Middle & 12,666 & 797 & 7,736 & 57.60 & 3.16 & 12,666 & 797 & 7,736 & 3.86 & .94 & 923 & 273 & 832 & 8.84 & 1.21 \\
\hline Older & 8,648 & 637 & 3,490 & 57.46 & 2.97 & 8,648 & 637 & 3,490 & 3.78 & .90 & 55 & 10 & 34 & 8.52 & 1.11 \\
\hline \multicolumn{16}{|l|}{ Rambouillet } \\
\hline Young & 6,716 & 539 & 6,716 & 61.42 & 3.50 & 6,716 & 539 & 6,716 & 4.50 & 1.20 & 4,912 & 529 & 4,912 & 8.19 & 1.32 \\
\hline Middle & 6,626 & 504 & 3,908 & 61.49 & 2.46 & 6,626 & 504 & 3,908 & 4.67 & 1.07 & 973 & 316 & 913 & 8.30 & 1.21 \\
\hline Older & 5,382 & 422 & 1,975 & 61.49 & 2.26 & 5,382 & 422 & 1,975 & 4.66 & .93 & 337 & 83 & 337 & 7.01 & 1.07 \\
\hline \multicolumn{16}{|l|}{ Targhee } \\
\hline Young & 5,457 & 536 & 5,457 & 59.61 & 2.50 & 5,457 & 536 & 5,457 & 4.65 & 1.26 & 4,434 & 511 & 4,434 & 8.91 & 1.62 \\
\hline Middle & 5,304 & 489 & 3,207 & 59.68 & 2.62 & 5,304 & 489 & 3,207 & 4.86 & .98 & 463 & 311 & 450 & 9.54 & 1.44 \\
\hline Older & 4,253 & 402 & 1,668 & 59.34 & 2.60 & 4,253 & 402 & 1,668 & 4.81 & .84 & - & - & - & - & - \\
\hline
\end{tabular}


Table 2. Estimates of variance components and fractions ${ }^{\mathrm{a}}$ of total variance for Columbia, Polypay, Rambouillet, and Targhee breeds for fleece traits with single-trait analyses by age of ewe

\begin{tabular}{|c|c|c|c|c|c|c|c|c|c|c|c|}
\hline \multirow[b]{2}{*}{ Traits } & \multicolumn{3}{|c|}{ Young age } & \multicolumn{4}{|c|}{ Middle ages } & \multicolumn{4}{|c|}{ Older ages } \\
\hline & $\mathrm{h}^{2}$ & $e^{2}$ & $\sigma_{\mathrm{p}}^{2}$ & $\mathrm{~h}^{2}$ & $\mathrm{pe}^{2}$ & $\mathrm{e}^{2}$ & $\sigma_{\mathrm{p}}^{2}$ & $\mathrm{~h}^{2}$ & $\mathrm{pe}^{2}$ & $e^{2}$ & $\sigma_{\mathrm{p}}^{2}$ \\
\hline \multicolumn{12}{|c|}{$\begin{array}{l}\text { Fleece grade, spinning } \\
\text { count }\end{array}$} \\
\hline Columbia & .40 & .60 & 6.20 & .45 & .06 & .49 & 6.46 & .37 & .09 & .54 & .540 \\
\hline Polypay & .47 & .54 & 6.68 & .44 & .00 & .56 & 6.82 & .47 & .00 & .53 & 6.74 \\
\hline Rambouillet & .46 & .54 & 8.24 & .32 & .00 & .68 & 4.97 & .32 & .00 & .68 & 4.62 \\
\hline Targhee & .36 & .63 & 5.30 & .38 & .06 & .56 & 6.10 & .32 & .11 & .57 & 6.00 \\
\hline \multicolumn{12}{|c|}{ Fleece weight, $\mathrm{kg}$} \\
\hline Columbia & .50 & .51 & .64 & .44 & .27 & .30 & .67 & .36 & .27 & .36 & .69 \\
\hline Polypay & .58 & .42 & .76 & .60 & .10 & .30 & .67 & .66 & .04 & .30 & .66 \\
\hline Rambouillet & .50 & .50 & .64 & .68 & .00 & .33 & .71 & .68 & .00 & .32 & .71 \\
\hline Targhee & .51 & .49 & .59 & .55 & .09 & .36 & .58 & .49 & .12 & .39 & .59 \\
\hline \multicolumn{12}{|c|}{ Staple length, $\mathrm{cm}$} \\
\hline Columbia & .53 & .47 & 1.18 & .40 & .25 & .35 & 1.13 & - & - & - & - \\
\hline Polypay & .62 & .37 & 2.11 & .66 & .09 & .25 & 1.18 & .78 & .03 & .18 & .65 \\
\hline Rambouillet & .46 & .55 & 1.10 & .60 & .00 & .41 & .71 & .86 & .00 & .14 & .90 \\
\hline Targhee & .55 & .44 & 1.24 & .55 & .16 & .29 & .82 & - & - & - & - \\
\hline
\end{tabular}

${ }^{a}{ }^{2}$, direct heritability; $\mathrm{pe}^{2}$, variance of permanent environmental effects of animals as fraction of total variance; $\mathrm{e}^{2}$, variance of residual as fraction of total variance; and $\sigma_{\mathrm{p}}^{2}$, phenotypic variance.

effects. In the model for single-trait analyses of measurements at the young age, permanent environmental and residual effects are combined in the e vector. With the three-trait analyses, the $\mathbf{u}_{\text {pe }}$ vector is used even for the young age in order to allow for an environmental covariance between records at different ages through the permanent environmental effects.

As described in the preceding article (Okut et al., 1999), although the environmental covariance due to an animal's permanent environmental effects in the different age classes can be forced into the covariance structure of permanent environmental effects across age classes, interpretation requires some caution when one class, such as the young age class, cannot have repeated measures. The combined (residual and permanent) environmental correlation can be correlated from the sum of the original residual and permanent environmental variance components and the permanent environmental covariance correlation between measures in the young and middle age classes:

$$
\begin{gathered}
r_{e_{y m}}=\left[r_{p e_{y m}}\left(p e_{y}^{2} \times p e_{m}^{2}\right) \cdot 5\right] \div \\
{\left[\left(p e_{y}^{2}+e_{y}^{2}\right)\left(p e_{m}^{2}+e_{m}^{2}\right)\right] \cdot 5}
\end{gathered}
$$

where $r_{p e_{y m}}$ is the correlation between permanent environmental effects, $\mathrm{pe}_{\mathrm{y}}^{2}$ and $\mathrm{pe}_{\mathrm{m}}^{2}$ are fractions of variance due to permanent environmental effects, and $e_{y}^{2}$ and $e_{m}^{2}$ are fractions of variance due to residual effects for the young $(\mathrm{y})$ and middle $(\mathrm{m})$ age classes.

Two fixed factors, year-sex combination and day in year shorn (indicator of contemporary group), were in the model for the young age classes. For the middle and older age classes, however, age of animal in years was added to the model as a fixed effect. Estimates of variance components with REML were obtained using a derivative-free algorithm (Smith and Graser, 1986; Graser et al., 1987) with the MTDFREML program of Boldman et al. (1993). Convergence was considered to have been obtained when the variance of the $-2 \mathrm{log}$ likelihoods in the simplex was less then $1 \times 10^{-6}$. Restarts were performed to obtain global convergence.

\section{Results}

The estimates of variance components and heritability estimates for fleece grade, fleece weight, and staple length obtained from single-trait analyses by age classes are given in Table 2 . In general, heritabilities of fleece grade decreased slightly with advancing ages of animal (averages of .42 for young, .40 for middle, and .37 for older age classes). On average, heritability of fleece grade was greatest for Polypay (.46) and smallest for Targhee (.35). In contrast to fleece grade, heritability estimates for fleece weight changed little with advancing age of animals (averages of .52, .57, and .55 from young to older). Heritability of fleece weight was greatest on average for Polypay (.61) and Rambouillet (.62) and smallest for Columbia (.43). The heritability estimates for fleece grade, a subjective score, were somewhat less than the average reported for fiber diameter, a quantitative measure, by F ogarty (1995). Heritability estimates for fleece weight were on the high end of the range of estimates reviewed by Fogarty (1995). 
Heritabilities of older age class for staple length in Columbia and Targhee could not be estimated because no observations were available for the older ewes of those breeds. Heritability estimates for staple length were somewhat greater than those for fleece grade and similar to those for fleece weight for the young and middle age classes, except for the two large estimates for the older age class for Polypay and Rambouillet that were based on few data. The heritability estimates were similar to those for FW. The averages for young and middle age classes were both .55.

The proportion of variance due to permanent environmental effects for fleece grade, fleece weight, and staple length ranged from low to moderate for all breeds and was generally not large except for fleece weight and staple length for Columbia. The sums of estimates of heritability and proportion of variance due to permanent environmental effects (repeatability) were relatively constant across breeds, especially for fleece weight; a smaller estimate of heritability was often paired with a larger estimate of fraction of variance due to permanent environmental effects.

\section{Multiple-Trait Analyses}

Estimates of (co)variance components and genetic parameters from threetrait (by age class) analyses for fleece grade and fleece weight and two-trait analyses for staple length are shown in Table 3. As with heritability estimates from single-trait analyses, estimates from three-trait analyses were relatively high and ranged from .32 to .52 for fleece grade and from .56 to .71 for fleece weight. Except for a few cases, heritabilities from three-trait analyses were greater than those from single-trait analyses. Averages of heritability estimates across breeds by age class were somewhat larger from the three-trait class analyses than from single-trait analyses; the largest differences were for fleece weight $(.63, .63$, and .66 vs $.52, .57$, and .55 by age class). Because for staple length either no records or only a few records were available for the older age class, only two-trait analyses were performed to estimate genetic parameters. Heritability estimates for this trait ranged from .52 (middle ages for Targhee) to .78 (middle ages for Polypay). Average estimates across ages and across breeds were larger from the two-trait analyses than from single-trait analyses.

A general guideline given by Robertson (1959) is that a genetic correlation greater than .80 indicates little need to divide the trait by age class.

Targhee had the largest estimates of genetic correlations between all pairs of age classes for fleece grade (.89 to .98). All estimates of genetic correlations among pairs of age classes for fleece grade for Polypay also were greater than .80. For Columbia and Rambouillet, only one of six estimates of genetic correlations was greater than .80 for fleece grade, and two of six estimates were near zero. On average across all breeds, only the genetic correlation between middle and older age classes exceeded .80 (.86).

For fleece weight, the average estimates of genetic correlations between age classes exceeded .80 (.81, .83, and .96). All genetic correlations for Columbia and Targhee were .90 or greater. For the correlation between middle and older age classes, all breeds had estimates that were .94 or larger. Genetic correlations for Rambouillet for young with middle and older age classes approached .80 (.76 and .74, respectively). The smallest estimates were .61 and .72 for Polypay between young and middle and young and older ages, respectively.

For staple length, the genetic correlation between young and middle age classes ranged from .69 to .94, with an average of .82 .

Proportion of variance due to permanent environmental effects of animal for fleece grade and fleece weight ranged from .00 to .22 with three-trait analyses. The proportions of variance due to this random effect were somewhat less than those from single-trait analyses. However, as with estimates obtained from single-trait analyses, proportions of variance due to permanent effects of animal for fleece grade were less than those for fleece weight with threetrait analyses. The proportions of variance due to permanent environmental effects of animal were greater for staple length than those for fleece weight with multiple-trait analyses. After combining variances due to permanent environmental and residual effect, the environmental correlations between pairs of age classes were generally near zero except for the young with middle age class for fleece weight for Polypay (.31) and staple length for Columbia (.35).

\section{Discussion}

In general, heritability estimates obtained from three-trait analyses were somewhat greater than those from single-trait analyses and those from previous studies (Fogarty, 1995; Notter and Hough, 1997). For fleece grade, heritability estimates with threetrait analyses for Polypay, Rambouillet, and Targhee agreed well with those of single-trait analyses. For fleece weight, heritability estimates for Polypay and Targhee and, in addition, estimates for middle and older age classes in Rambouillet, agreed well with those from single-trait analyses. For staple length, however, heritability estimates for older Columbia and Polypay ewes and heritability for young Rambouillet ewes differed considerably from those derived from single-trait estimates. Many studies have reported that genetic parameter estimates for the same data with single and multiple-trait analyses differ in certain situations ( $\mathrm{L}$ in and Lee, 1986; Buttazoni and Mao, 1989; Keeton et al. 1996; Satoh et al., 1997). However, the differences in estimates between single- and three-trait analyses in this study 
Table 3. Estimates ${ }^{a}$ of (co)variance components and fractions of variances for Columbia (C), Polypay (P), Rambouillet (R), and Targhee (T) breeds for fleece traits with three-trait analyses

\begin{tabular}{|c|c|c|c|c|c|c|c|c|c|c|c|c|}
\hline \multirow[b]{2}{*}{ Parameter } & \multicolumn{4}{|c|}{ Fleece grade, spinning count } & \multicolumn{4}{|c|}{ Fleece weight, $\mathrm{kg}$} & \multicolumn{4}{|c|}{ Staple length, cm } \\
\hline & C & $\mathrm{P}$ & $\mathrm{R}$ & $\mathrm{T}$ & C & $\mathrm{P}$ & $\mathrm{R}$ & $\mathrm{T}$ & C & $\mathrm{P}$ & $\mathrm{R}$ & $\mathrm{T}$ \\
\hline$h_{a y}^{2}$ & .52 & .47 & .44 & .40 & .65 & .56 & .68 & .62 & .54 & .62 & .56 & .59 \\
\hline $\mathrm{h}_{\mathrm{am}}^{2}$ & .47 & .44 & .32 & .44 & .57 & .59 & .69 & .66 & .53 & .78 & .57 & .52 \\
\hline $\mathrm{h}_{\mathrm{ao}}^{2}$ & .45 & .44 & .34 & .41 & .62 & .71 & .70 & .59 & - & - & - & - \\
\hline$r_{\text {aym }}$ & .74 & .83 & .34 & .96 & .95 & .61 & .76 & .92 & .86 & .69 & .79 & .94 \\
\hline$r_{\text {ayo }}$ & -.01 & .82 & .00 & .89 & .95 & .72 & .74 & .90 & - & - & - & - \\
\hline$r_{\text {amo }}$ & .66 & .91 & .88 & .98 & .95 & .96 & .94 & .98 & - & - & - & - \\
\hline $\mathrm{pe}_{\mathrm{y}}^{2}$ & .22 & .00 & .00 & .00 & .07 & .21 & .15 & .20 & .32 & .08 & .10 & .01 \\
\hline $\mathrm{pe}_{\mathrm{m}}^{2}$ & .00 & .00 & .01 & .02 & .15 & .09 & .00 & .00 & .11 & .00 & .02 & .14 \\
\hline $\mathrm{pe}_{\mathrm{o}}^{2}$ & .06 & .00 & .00 & .04 & .07 & .00 & .00 & .05 & - & - & - & - \\
\hline$r_{\text {eym }}$ & .00 & .00 & .00 & .01 & .13 & .31 & .00 & .00 & .35 & .03 & .10 & .08 \\
\hline$r_{\text {eyo }}$ & .00 & .00 & .00 & .00 & -.05 & .02 & .00 & .01 & - & - & - & - \\
\hline$r_{e m o}$ & .00 & .00 & .00 & .00 & .18 & .01 & .00 & .02 & - & - & - & - \\
\hline$e_{y}^{2}$ & .25 & .53 & .56 & .60 & .28 & .24 & .17 & .18 & .14 & .30 & .34 & .40 \\
\hline$e_{m}^{2}$ & .53 & .56 & .67 & .54 & .28 & .32 & .31 & .34 & .35 & .22 & .41 & .34 \\
\hline $\mathrm{e}_{\mathrm{o}}^{2}$ & .49 & .55 & .65 & .54 & .30 & .29 & .30 & .36 & - & - & - & - \\
\hline$\sigma_{y}^{2}$ & 6.63 & 6.74 & 8.21 & 5.40 & .73 & .71 & .65 & .63 & 1.18 & 1.78 & .89 & .94 \\
\hline$\sigma_{\mathrm{m}}^{2}$ & 6.07 & 6.83 & 5.16 & 6.34 & .74 & .62 & .73 & .63 & 1.21 & 1.27 & .69 & .82 \\
\hline$\sigma_{0}^{2}$ & 5.75 & 6.65 & 4.69 & 6.30 & .82 & .67 & .76 & .65 & - & - & - & - \\
\hline
\end{tabular}

for some breeds are not as large as those from other studies, although most of those studies did not involve missing observations. Satoh et al. (1997) noted that multivariate analysis uses the phenotypic information on all traits, but univariate analysis does not. As a consequence, the multivariate analysis should account for selection at earlier ages and yield better estimates of variance and covariance components than univariate analysis. This study supports that idea. In singletrait analyses in this study, only pedigree information of the age group being analyzed was used in mixedmodel equations. In multipletrait analyses, however, pooled pedigree information was used. Thus, for young Polypay ewes, for example, pedigree information on 13,432 animals was used in the single-trait analysis, whereas for multiple-trait analyses pedigree information on 24,746 animals was used.

For fleece grade, direct genetic correlations between young and older ages for Columbia and between young and older and between young and middle ages for Rambouillet were $-.01, .00$, and .34 , respectively, indicating that this trait may need to be defined by age of animal for both Columbia and Rambouillet breeds. For fleece grade, all genetic correlations between pairs of ages for Targhee and Polypay and correlation between middle and older age classes for Rambouillet were greater than .80. Genetic correlations across ages for objective measurements of fiber diameter (fleece grade) in Australian Merino sheep have been reported to exceed .80 (Coelli et al., 1998). Likewise, for fleece weight, all genetic correlations between pairs of age classes and correlations between middle and older ages for Polypay and Rambouillet were greater than .80. Hence, these age classes could be treated as one trait rather than three and could be treated as one trait for selection, based on Robertson's (1959) guideline. In addition, genetic correlations for staple length between young and middle ages for Columbia, Polypay, and Rambouillet were greater than .80, indicating young and middle ages are essentially one trait rather than two because causal effects for the classes are similar. Coelli et al. (1998) found that genetic correlations across ages for clean fleece weight in Australian Merino sheep of less than .80 existed between yearling and adult ages but not among adult ages. Genetic correlations between some pairs of ages for fleece grade, fleece weight, and staple length are in the range of .70 to .79 , indicating that further studies may be needed to reach a general conclusion for these ages and traits. 


\section{Implications}

Genetic correlations between fleece grade at different ages for some breeds were low. If the genetic correlation between age classes is low, more progress can be made in selection programs by considering the age of animal as a part of the definition of the trait. Direct genetic correlations for fleece grade between young and older ages for Columbia and between young and older and between young and middle ages for Rambouillet were low, indicating that this trait may need to be defined by two or three age classes for these breeds. Genetic correlations between many pairs of ages are greater than .80 with similar heritabilities and phenotypic variance. These age classes can be considered as one trait, rather than three, for selection. Genetic correlations between some pairs of ages for fleece traits of some breeds were moderately large (.70 to .79), so further study will be needed to reach a general conclusion about whether these traits should be defined by age of animals.

\section{Literature Cited}

Atkins, K. D. 1990. Incorporating parameters for lifetime productivity into breeding objectives for sheep. Proc. 4th World Congr. Genet. Appl. Livest. Prod. 15:17-26.

Atkins, K. D., and S. I. Mortimer. 1987. The relationship between hogget and adult wool traits in Merino sheep. Proc. 6th Conf. Aust. Assoc. Anim. Breed. Genet. 4:79-82.

Boldman, K. G., L. A. Kriese, S. D. Kachman, and L. D. Van Vleck. 1993. A manual for the use of MTDFREML. ARS, USDA, Clay Center, NE.

Buttazzoni, L., and I. L. Mao. 1989. Genetic parameters of estimated net energy efficiencies for milk production, and body weight change in dairy cows. J. Dairy Sci. 72:671-677.

Coelli, K. A., A. R. Gilmour, and K. D. Atkins. 1998. Comparison of genetic covariance models for annual measurements of fleece weight and fibre diameter. Proc. 6th World Congr. Genet. Appl. Livest. Prod. Vol. 24:31-34.

Ercanbrack, S. K., and A. D. Knight. 1998. Responses to various selection protocols for lamb production in Rambouillet, Targhee, Columbia, and Polypay sheep. J. Anim. Sci. 76: 1311-1325.

Falconer, D. S. 1952. The problem of environment and selection. Am. Nat. 86:293-298.

Fogarty, N. M. 1995. Genetic parameters for live weight, fat and muscle measurements, wool production and reproduction in sheep: A review. Anim. Breed. Abstr. 63:101-143.

Graser, H.-U., S. P. Smith, and B. Tier. 1987. A derivative-free approach for estimating variance components in animal models by restricted maximum likelihood. J . Anim. Sci. 64:1362-1370.

Iman, N. Y., C. L. J ohnson, W. C. Russell, and R. H. Stobart. 1992. Estimation of genetic parameters for wool fiber diameter measures. J. Anim. Sci. 70:1110-1115.

Keeton, L. L., R. D. Green, B. L. Golden, and K. J . Anderson. 1996. Estimation of variance components and prediction of breeding values for scrotal circumference and weaning weight in Limousin cattle. J. Anim. Sci. 74:31-36.

Lin, Y. C., and A. J . Lee. 1986. Sequential estimation of genetic and phenotypic parameters in multivariate mixed model analyses. J. Dairy Sci. 69:2696-2703.

Notter, D. R., and J. D. Hough. 1997. Genetic parameter estimates for growth and fleece characteristics in Targhee sheep. J . Anim. Sci. 75:1729-1737.

Okut, H., C. M. Bromley, L. D. Van Vleck, and G. D. Snowder. 1999. Genotypic expression at different ages: I. Prolificacy traits of sheep. J . Anim. Sci. 77:2357-2365.

Robertson, A. 1959. The sampling variance of the genetic correlation coefficient. Biometrics 15:469-485.

Saboulard, M., W. C. Russell, and M. L. Riley. 1995. Selection for lambing rate and clean fleece weight in sheep. J . Anim. Sci. 73: 3195-3198.

Satoh, M., A. Nishida, J .A.M. van Arendonk, and T. van der Lende. 1997. Benefit of multiple trait selection to increase reproductive traits: Experimental evidence from golden hamsters. J . Anim. Sci. 75:3103-3113.

Smith, S. P., and H.-U. Graser. 1986. Estimating variance components in a class of mixed models by restricted maximum likelihood. J. Dairy Sci. 69:1156-1165.

van Zyl, C. M. 1998. Genetic parameters of growth, reproduction and wool traits in Columbia, Polypay, Rambouillet and Targhee breeds. In: Ph.D. dissertation. Univ. of Nebraska, Lincoln. 